\title{
Inhibited growth of Pseudomonas aeruginosa by dextran- and polyacrylic acid-coated ceria nanoparticles
}

This article was published in the following Dove Press journal:

International Journal of Nanomedicine

29 August 2013

Number of times this article has been viewed

\author{
Qi Wang' \\ J Manuel Perez ${ }^{2}$ \\ Thomas J Webster ${ }^{1,3}$ \\ 'Bioengineering Program, College of \\ Engineering, Northeastern University, \\ Boston, MA, USA; ${ }^{2}$ Nanoscience \\ Technology Center, University of \\ Central Florida, Orlando, FL, USA; \\ ${ }^{3}$ Department of Chemical Engineering, \\ College of Engineering, Northeastern \\ University, Boston, MA, USA
}

Correspondence: Thomas J Webster Department of Chemical Engineering, Northeastern University, 360 Huntington Avenue, Boston,

MA 02। I5, USA

Tel +I 6173736585

Email th.webster@neu.edu

\begin{abstract}
Ceria $\left(\mathrm{CeO}_{2}\right)$ nanoparticles have been widely studied for numerous applications, but only a few recent studies have investigated their potential applications in medicine. Moreover, there have been almost no studies focusing on their possible antibacterial properties, despite the fact that such nanoparticles may reduce reactive oxygen species. In this study, we coated $\mathrm{CeO}_{2}$ nanoparticles with dextran or polyacrylic acid (PAA) because of their enhanced biocompatibility properties, minimized toxicity, and reduced clearance by the immune system. For the first time, the coated $\mathrm{CeO}_{2}$ nanoparticles were tested in bacterial assays involving Pseudomonas aeruginosa, one of the most significant bacteria responsible for infecting numerous medical devices. The results showed that $\mathrm{CeO}_{2}$ nanoparticles with either coating significantly inhibited the growth of Pseudomonas aeruginosa, by up to $55.14 \%$, after 24 hours compared with controls (no particles). The inhibition of bacterial growth was concentration dependent. In summary, this study revealed, for the first time, that the characterized dextran- and PAA-coated $\mathrm{CeO}_{2}$ nanoparticles could be potential novel materials for numerous antibacterial applications.
\end{abstract}

Keywords: antibacterial, biomedical applications

\section{Introduction}

Among the rare earth elements (the 15 lanthanides, along with scandium and yttrium), cerium is the most abundant element, at $66.5 \mathrm{ppm}$ in the Earth's crust compared with copper (60 ppm) or tin (2.3 ppm). ${ }^{1,2}$ As a highly abundant material, ceria (or cerium oxide $\left[\mathrm{CeO}_{2}\right]$ ) is technologically important due to its wide range of applications, for example, in catalysts for the elimination of toxic auto exhaust gases, ${ }^{3,4}$ oxygen sensors, ${ }^{5,6}$ fuel cells, ${ }^{7-9}$ electrochromic thin films, ${ }^{10,11}$ and so on. Upon the transition from a macrosized particle to a nanocrystalline particle, $\mathrm{CeO}_{2}$ significantly changes its physicochemical properties to, usually, possess a high density of nanocrystalline $\mathrm{CeO}_{2}$ interfaces. ${ }^{12}$ Thus, nanostructured $\mathrm{CeO}_{2}$ has attracted extensive attention in the field of nanotechnology due to improvements in redox properties, transport properties, and high surface to volume ratios, which may be of value for various biological applications.

However, although $\mathrm{CeO}_{2}$ nanoparticles have been studied for numerous traditional scientific and engineering applications, there have been almost no studies regarding the potential biomedical applications of $\mathrm{CeO}_{2}$ until recently, when researchers demonstrated that $\mathrm{CeO}_{2}$ nanoparticles possess antioxidant properties at physiological $\mathrm{pH}$ values. The ability of these nanoparticles to act as an antioxidant lies in their ability to reversibly switch from $\mathrm{Ce}^{3+}$ to $\mathrm{Ce}^{4+} .{ }^{13}$ In recent studies, this antioxidative ability enabled the application of $\mathrm{CeO}_{2}$ nanoparticles to protect against radiation damage, oxidative stress, and inflammation. ${ }^{14-16}$ For example, Tsai et al reported 
that free radical scavenging could be achieved in murine insulinoma $\beta$ TC-tet cells by the introduction of crystalline $\mathrm{CeO}_{2}$ nanoparticles. ${ }^{17}$

Moreover, in previous studies, due to safety concerns for biomedical applications, the toxicity of zinc oxide $(\mathrm{ZnO})$, $\mathrm{CeO}_{2}$, and titanium oxide $\left(\mathrm{TiO}_{2}\right)$ was compared based on dissolution and oxidative stress properties. ${ }^{18,19}$ The results showed that the $\mathrm{CeO}_{2}$ nanoparticles could suppress the generation of reactive oxygen species (ROS) and induce cellular resistance to an exogenous source of oxidative stress, to protect cells from oxidation injury. However, concerns over $\mathrm{CeO}_{2}$ toxicity, biocompatibility, and avoidance of immune-system clearance remained. Thus, to further improve the clinical use of $\mathrm{CeO}_{2}$ nanoparticles, previous efforts have coated $\mathrm{CeO}_{2}$ with biocompatible dextran and PAA; enhanced stability in aqueous solutions has also been reported for these coated $\mathrm{CeO}_{2}$ nanoparticles. ${ }^{15,31}$

To build on these exciting medical applications of $\mathrm{CeO}_{2}$ nanoparticles, the present study investigated, for the first time, the influence of dextran- and PAA-coated $\mathrm{CeO}_{2}$ nanoparticles on bacteria growth. Pseudomonas aeruginosa is an aerobic gram-negative bacterium that is an important cause of various infections, especially in hospitals. Hospitalized patients may be colonized with $P$. aeruginosa on admission or during their hospital stay, and $P$. aeruginosa can be isolated from nearly any conceivable source within hospitals. ${ }^{20,21}$ It accounts for $11 \%-13.8 \%$ of all nosocomial infections when a microbiological isolate is identifiable. ${ }^{22}$ Infections caused by $P$. aeruginos $a$ are not only common, ${ }^{23,24}$ but are also associated with high morbidity and mortality when compared with other bacterial pathogens. ${ }^{25,26}$ An additional concern involves the increased antimicrobial resistance of nosocomial $P$. aeruginosa isolates. ${ }^{27}$ Even more troublesome, P. aeruginosa attaches to both biotic and abiotic surfaces, forming a biofilm. Once formed, the $P$. aeruginosa infections are much more difficult to treat, due to their formation of exopolysaccharides. Biofilms of $P$. aeruginosa have been found on numerous medical devices, including central venous catheters, contact lenses, mechanical heart valves, intrauterine devices, and indwelling urinary catheters. ${ }^{28,29}$ Thus, it is significant to develop active and biocompatible molecules that do not rely on antibiotics, to which bacteria may develop a resistance, and that kill bacteria at early stages of infections, before biofilm formation.

Therefore in this study, for the first time, due to concerns over the biocompatibility, toxicity, and immune system clearance of pristine $\mathrm{CeO}_{2}$ nanoparticles, we investigated the effectiveness of dextran- and PAA-coated $\mathrm{CeO}_{2}$ nanoparticles in inhibiting bacterial growth, specifically, $P$. aeruginosa. The results showed that such coated $\mathrm{CeO}_{2}$ nanoparticles significantly inhibited the growth of P. aeruginosa, revealing a promising application of $\mathrm{CeO}_{2}$ nanoparticles to prevent bacterial infections that should be further explored.

\section{Materials and methods Synthesis, coating, and characterization of the cerium oxide nanoparticles}

The dextran- or PAA-coated $\mathrm{CeO}_{2}$ nanoparticles were synthesized according to previously described procedures. ${ }^{15,30,31}$ Briefly, a solution of cerium (III) nitrate $(1.0 \mathrm{M}$, 99\%) (Sigma-Aldrich Corp, St Louis, MO, USA) in water $(5.0 \mathrm{~mL})$ was mixed with an aqueous solution of either PAA (0.5 M) (Sigma-Aldrich Corp) or dextran (1.0 M) (SigmaAldrich Corp). The resulting mixtures were then added to an ammonium hydroxide solution $(30.0 \mathrm{~mL}, 30 \%)$ (SigmaAldrich Corp) under continuous stirring for 24 hours, at room temperature. The preparation was then centrifuged at $4000 \mathrm{rpm}$ for two 30-minute cycles to settle down any debris and large agglomerates. The supernatant solution was then purified from free polymers and other reagents and then concentrated using a $30 \mathrm{~K}$ Amicon ${ }^{\circledR}$ Ultra-4 Centrifugal Filter Units (EMD Millipore Corp, Billerica, MA, USA). The final dextran- and PAA-coated $\mathrm{CeO}_{2}$ nanoparticle preparations were stored at a $1.5 \mathrm{mg} \mathrm{CeO}_{2} / \mathrm{mL}$ concentration in deionized water until further used; such concentrations have previously been shown to be nontoxic to mammalian cells. ${ }^{15,30,31}$

The various polymer-coated $\mathrm{CeO}_{2}$ nanoparticle preparations were characterized by dynamic light scattering (DLS) to determine the size, zeta potential, and surface charge of the nanoparticles (Zetasizer; Malvern Instruments Ltd, Malvern, UK). Fourier transform infrared (FTIR) spectrometry analysis was performed on vacuum dried samples to verify the surface functionalities of the nanoparticles (Spectrum $^{\text {TM }} 100$ Optica; PerkinElmer Inc, Waltham, MA, USA).

\section{Bacterial assays}

A bacteria cell line of $P$. aeruginosa was obtained in freezedried form from the American Type Culture Collection (catalog number 27853; Manassas, VA, USA). The bacterial cells were propagated in $30 \mathrm{mg} / \mathrm{mL}$ tryptic soy broth (TSB) (catalog number 22092; Sigma-Aldrich Corp) for 24 hours in an incubator $\left(37^{\circ} \mathrm{C}\right.$, humidified, $5 \%$ carbon dioxide). When the second passage of bacteria reached its stationary phase, 
the second passage was frozen in one part TSB and one part $40 \%$ sterile glycerol (catalog number G5516; Sigma-Aldrich Corp). Before bacterial seeding, a sterile $10 \mu \mathrm{L}$ loop was used to withdraw bacteria from the prepared frozen stock, the bacteria were streaked onto a TSB Agar plate (catalog number A1296; Sigma-Aldrich Corp), and the TSB agar plate was incubated for 20 hours, to form single bacterial colonies. Then, a single colony was collected using a sterile loop and was incubated in a $15 \mathrm{~mL}$ sterile test tube containing $3 \mathrm{~mL}$ of TSB, for 20 hours. The bacterial solution was diluted to a concentration of $10^{7}$ bacteria/mL, which was assessed by measuring the optical density of the bacterial solution, using a standard curve correlating optical densities and bacterial concentrations. The optical densities were measured at $562 \mathrm{~nm}$, using a SpectraMax M5 Microplate Reader (Molecular Devices LLC, Sunnyvale, CA, USA).

Two concentrations of both dextran- or PAA-coated $\mathrm{CeO}_{2}$ nanoparticles were separately tested against bacterial growth. The solutions of $\mathrm{CeO}_{2}$ nanoparticles were mixed with bacterial solutions $\left(10^{7}\right.$ bacteria/mL) at a $1: 10$ or $1: 5$ volume ratio and cultured for either 1,6 , or 24 hours in the incubator. Solutions of sterile TSB were mixed with bacteria solutions as blank controls. After the treatment, the solutions with bacteria were diluted with a phosphate-buffered saline (PBS) (catalog number P4417; Sigma-Aldrich Corp) solution and were spread on agar plates, and the bacteria colonies were counted after 18 hours of incubation.

Bacterial tests were conducted in triplicate and repeated three times. Data were collected, and the differences were assessed with the probability associated with a one-tailed Student's $t$-test. Statistical analyses were performed using Microsoft ${ }^{\circledR}$ Excel $^{\circledR}$ 2010 (Microsoft Corporation, Redmond, WA, USA).

\section{Results and discussion Cerium oxide nanoparticle characterization}

The $\mathrm{CeO}_{2}$ nanoparticle preparations used in this study were aqueous suspensions of nanoparticles coated with either PAA or dextran. The synthetic procedure used to make these nanoparticles is highly reproducible and yielded nanoparticles with a $\mathrm{CeO}_{2}$ core of 3-4 $\mathrm{nm}$, by transmission electron microscopy (TEM). ${ }^{15,30,31}$ Specifically, the hydrodynamic diameter of the PAA-coated $\mathrm{CeO}_{2}$ nanoparticles was $5 \mathrm{~nm}$, while the size for the dextran-coated $\mathrm{CeO}_{2}$ nanoparticles was $14 \mathrm{~nm} .{ }^{15,30,31}$ Confirmation of the polymer coating was accessed by FTIR, as previously described, ${ }^{15,30,31}$ and by zeta potential, confirming the presence of a highly negative charged polymer coating for the PAA-coated $\mathrm{CeO}_{2}$ nanoparticles $(\zeta=-45 \mathrm{mV})$ and a lower negative charge (close to neutral) for the dextran-coated $\mathrm{CeO}_{2}$ nanoparticles $(\zeta=-2 \mathrm{mV})$.

\section{Bacterial assays}

As shown in Figures 1 and 2, the $\mathrm{CeO}_{2}$ nanoparticles did not show significant inhibition of $P$. aeruginosa growth compared with the TSB controls after 1 hour of treatment. However, after 6 hours of treatment, both concentrations of the dextran-coated $\mathrm{CeO}_{2}$ nanoparticles were found to have significantly inhibited the growth of $P$. aeruginosa, by about $20 \%$ compared with the TSB controls $(P<0.05)$. The PAAcoated $\mathrm{CeO}_{2}$ nanoparticles showed significant inhibition of $P$. aeruginosa growth only for the higher concentration (bacterial solution: $\mathrm{CeO}_{2}$ nanoparticles $=5: 1$ ).

Most importantly, the growth of $P$. aeruginosa was strongly inhibited in the presence of either the dextran- or PAA-coated $\mathrm{CeO}_{2}$ nanoparticles after 24 hours compared

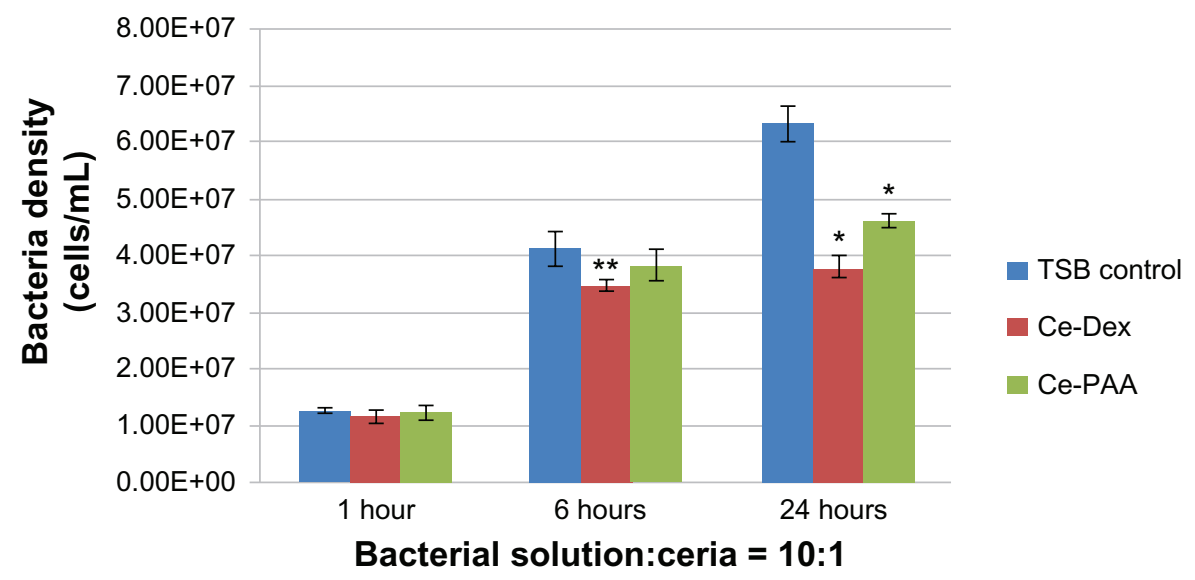

Figure I Inhibited Pseudomonas aeruginosa growth in the presence of ceria nanoparticles at three time points tested (I, 6, and 24 hours).

Notes: The volume ratio of bacterial solution $\left(10^{7}\right.$ bacteria/mL) and ceria nanoparticles was $10: 1$. Data is represented as mean \pm standard deviation, $\mathrm{n}=3 ; * P<0.0 \mathrm{I}$ compared with the TSB control group, after 24 hours of treatment. $* * P<0.05$ compared with the TSB control group, after 6 hours of treatment. Abbreviations: Ce, ceria; Dex, dextran; PAA, polyacrylic acid; TSB, tryptic soy broth. 


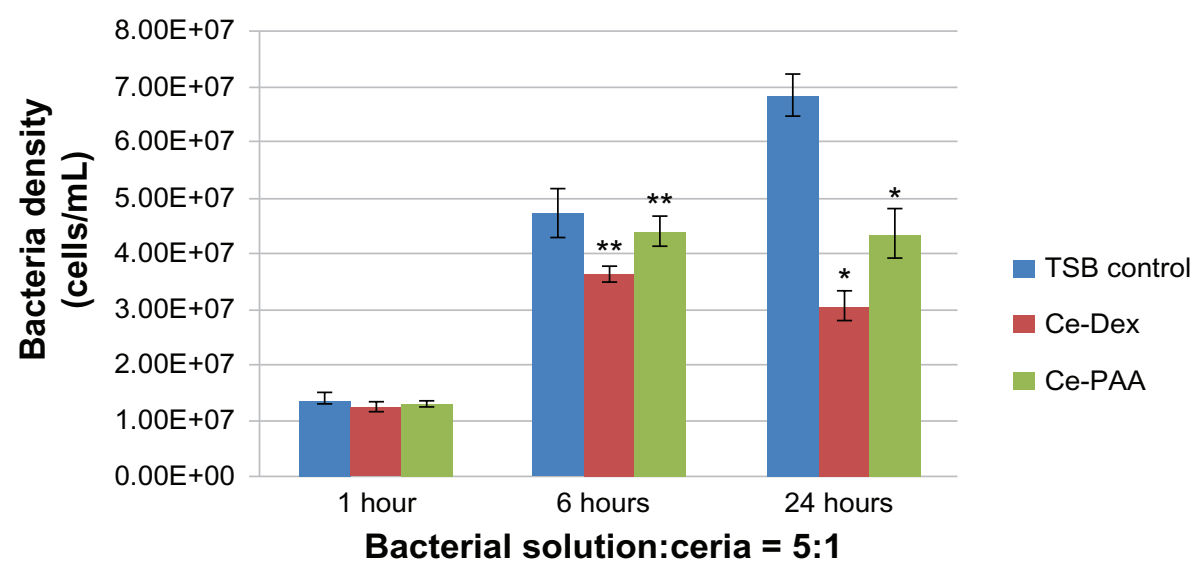

Figure 2 Pseudomonas aeruginosa growth in the presence of ceria nanoparticles at three time points tested (I, 6, and 24 hours).

Notes: The volume ratio of bacterial solution $\left(10^{7}\right.$ bacteria $\left./ \mathrm{mL}\right)$ and ceria nanoparticles was $5: \mathrm{I}$. Data is represented as mean \pm standard deviation, $\mathrm{n}=3 ; * P<0.0 \mathrm{I}$ compared with the TSB control group, after 24 hours of treatment. **P $<0.05$ compared with the TSB control group after, 6 hours of treatment.

Abbreviations: Ce, ceria; Dex, dextran; PAA, polyacrylic acid; TSB, tryptic soy broth.

with the TSB controls $(P<0.01)$. When the volume ratio of bacterial solution to $\mathrm{CeO}_{2}$ nanoparticles was $10: 1$, P. aeruginosa growth was inhibited by $40.12 \%$ and $26.88 \%$ in the presence of dextran- and $\mathrm{PAA}$-coated $\mathrm{CeO}_{2}$ nanoparticles, respectively, compared with the TSB controls. When the concentration of $\mathrm{CeO}_{2}$ nanoparticles doubled, the inhibition of $P$. aeruginosa growth reached $55.41 \%$ and $36.44 \%$ for the dextran- and PAA-coated $\mathrm{CeO}_{2}$ nanoparticles, respectively. Critically, all of this inhibition occurred without the use of antibiotics, with only the use of the $\mathrm{CeO}_{2}$ nanoparticles.

Based on the results of bacterial assays, the inhibition to $P$. aeruginosa growth by dextran- and PAA-coated $\mathrm{CeO}_{2}$ nanoparticles was more significant as the treatment time increased to 24 hours. In addition, the dextran-coated $\mathrm{CeO}_{2}$ nanoparticles showed a stronger inhibition of bacterial growth than did the PAA-coated $\mathrm{CeO}_{2}$ nanoparticles, especially after treatment for 6 and 24 hours. One possible reason the dextran coating and PAA coating could affect the bacterial growth differently is that the size of the dextrancoated $\mathrm{CeO}_{2}$ nanoparticles was $14 \mathrm{~nm}$ and the size of PAAcoated $\mathrm{CeO}_{2}$ nanoparticles was $5 \mathrm{~nm}$, which translates to an altered ability to interact with bacteria membranes. In addition, as mentioned, the surface energy of the dextran- and PAA-coated $\mathrm{CeO}_{2}$ nanoparticles was different, which could also have strongly influenced their interactions with bacteria cell membranes. Moreover, as expected, from 6 hours to 24 hours, the bacteria propagated quickly in the TSB control, but the bacteria numbers decreased even more during this time period with the treatment with both kinds of coated $\mathrm{CeO}_{2}$ nanoparticles.

Importantly, the mechanism of how dextran- and PAAcoated $\mathrm{CeO}_{2}$ nanoparticles prevented bacterial growth remains unexplored. Since $\mathrm{CeO}_{2}$ nanoparticles have been shown to suppress the generation of ROS, ${ }^{19}$ their antibacterial properties demonstrated here, for the first time, could be different from those of many other nanoparticles (such as $\mathrm{ZnO}$ nanoparticles, silver [Ag] nanoparticles, and so on) that are believed to kill bacteria mainly through the generation of ROS. Although requiring additional investigation, the possible mechanism for the antibacterial action of the coated $\mathrm{CeO}_{2}$ nanoparticles formulated here could be that the dextran and PAA coatings interacted with specific proteins on the bacterial cell membranes to alter the permeability of the cell membranes, thus, killing the bacterial cells. Moreover, it is possible that the dextran or PAA coated $\mathrm{CeO}_{2}$ nanoparticles studied here may have promoted the adsorption, from the TSB, of proteins that are known to inhibit bacteria growth (such as fibronectin, mucin, vitronectin, etc). ${ }^{32}$ Future studies should also investigate how universal such bacterial inhibition is, by exposing such coated $\mathrm{CeO}_{2}$ nanoparticles to other bacteria (such as Staphylococcus aureus and Escherichia coli).

\section{Conclusion}

In conclusion, the growth of $P$. aeruginosa was significantly inhibited in the presence of either dextran- or PAA-coated $\mathrm{CeO}_{2}$ nanoparticles after 24 hours. The effectiveness of bacterial-growth inhibition reached $55.41 \%$ for the dextrancoated $\mathrm{CeO}_{2}$ nanoparticles compared with the TSB control. This study revealed, for the first time, that the characterized coated $\mathrm{CeO}_{2}$ nanoparticles could potentially serve as a novel antibacterial agent in biomedical applications. Further studies, such as investigation of longer-term treatment and elucidating the mechanism of action, are important 
to achieve a better understanding and the application of such coated $\mathrm{CeO}_{2}$ nanoparticles in numerous antibacterial applications.

\section{Acknowledgments}

The authors thank Northeastern University and the University of Central Florida for funding.

\section{Disclosure}

The authors report no conflicts of interest in this work.

\section{References}

1. Ahrens TJ, editor. Global Earth Physics: A Handbook of Physical Constants. Washington, DC: American Geophysical Union; 1995.

2. Lide D, editor. CRC Handbook of Chemistry and Physics. 88th ed. Boca Raton, FL: CRC Publishing Co; 2007.

3. Trovarelli A. Catalytic properties of ceria and $\mathrm{CeO} 2$-containing materials. Catalysis Reviews. 1996;38(4):439-520.

4. Kašpar J, Fornasiero P, Graziani M. Use of $\mathrm{CeO} 2$-based oxides in the three-way catalysis. Catalysis Today. 1999;50(2):285-298.

5. Beie HJ, Gnörich A. Oxygen gas sensors based on $\mathrm{CeO} 2$ thick and thin-films. Sens Actuators B Chem. 1991;4(3-4):393-399.

6. Jasinski P, Suzuki T, Anderson HU. Nanocrystalline undoped ceria oxygen sensor. Sens Actuators B Chem. 2003;95(1-3):73-77.

7. Park S, Vohs JM, Gorte RJ. Direct oxidation of hydrocarbons in a solid-oxide fuel cell. Nature. 2000;404(6775):265-267.

8. Sun C, Hui R, Roller J. Cathode materials for solid oxide fuel cells: a review. J Solid State Electrochem. 2010;14(7):1125-1144.

9. Sun C, Stimming U. Recent anode advances in solid oxide fuel cells. J Power Sources. September 27, 2007;171(2):247-260.

10. Porqueras I, Person C, Corbella C, Vives M, Pinyol A, Bertan E. Characteristics of e-beam deposited electrochromic $\mathrm{CeO} 2$ thin films. Solid State Ionics. 2003;165(1-4):131-137.

11. Özer N. Optical properties and electrochromic characterization of sol-gel deposited ceria films. Solar Energy Materials and Solar Cells. 2001;68(3-4):391-400.

12. Ivanov VK, Usatenko AV, Shcherbakov AB. Antioxidant activity of nanocrystalline ceria to anthocyanins. Russian Journal of Inorganic Chemistry. 2009;54(10):1522-1527.

13. Tarnuzzer RW, Colon J, Patil S, Seal S. Vacancy engineered ceria nanostructures for protection from radiation-induced cellular damage. Nano Lett. 2005;5(12):2573-2577.

14. Das M, Patil S, Bhargava N, et al. Auto-catalytic ceria nanoparticles offer neuroprotection to adult rat spinal cord neurons. Biomaterials. 2007;28(10):1918-1925.

15. Perez JM, Asati A, Nath S, Kaittanis C. Synthesis of biocompatible dextran-coated nanoceria with $\mathrm{pH}$-dependent antioxidant properties. Small. 2008;4(5):552-556.
16. Lee SS, Zhu H, Contreras EQ, Prakash A, Puppala HL, Colvin VL. High temperature decomposition of cerium precursors to form ceria nanocrystal libraries for biological applications. Chem Mater. 2012;24(3):424-432.

17. Tsai YY, Oca-Cossio J, Agering K, et al. Novel synthesis of cerium oxide nanoparticles for free radical scavenging. Nanomedicine (Lond). 2007;2(3):325-332.

18. Nel A, Xia T, Mädler L, Li N. Toxic potential of materials at the nanolevel. Science. 2006;311(5761):622-627.

19. Xia T, Kovochich M, Liong M, et al. Comparison of the mechanism of toxicity of zinc oxide and cerium oxide nanoparticles based on dissolution and oxidative stress properties. ACS Nano. 2008;2(10):2121-2134.

20. Bonten MJ, Bergmans DC, Speijer H, Stobberingh EE. Characteristics of polyclonal endemicity of Pseudomonas aeruginosa colonization in intensive care units. Implications for infection control. Am J Respir Crit Care Med. 1999;160(4):1212-1219.

21. Pirnay JP, De Vos D, Cochez C, et al. Molecular epidemiology of Pseudomonas aeruginosa colonization in a burn unit: persistence of a multidrug-resistant clone and a silver sulfadiazine-resistant clone. J Clin Microbiol. 2003;41(3):1192-1202.

22. Lizioli A, Privitera G, Alliata E, et al. Prevalence of nosocomial infections in Italy: result from the Lombardy survey in 2000. $J$ Hosp Infect. 2003;54(2):141-148.

23. Rello J, Ollendorf DA, Oster G, et al; VAP Outcomes Scientific Advisory Group. Epidemiology and outcomes of ventilator-associated pneumonia in a large US database. Chest. 2002;122(6):2115-2121.

24. Kollef MH, Shorr A, Tabak YP, Gupta V, Liu LZ, Johannes RS. Epidemiology and outcomes of health-care-associated pneumonia: results from a large US database of culture-positive pneumonia. Chest. 2005;128(6):3854-3862.

25. Osmon S, Ward S, Fraser VJ, Kollef MH. Hospital mortality for patients with bacteremia due to Staphylococcus aureus or Pseudomonas aeruginosa. Chest. 2004;125(2):607-616.

26. Harbarth S, Ferrière K, Hugonnet S, Ricou B, Suter P, Pittet D. Epidemiology and prognostic determinants of bloodstream infections in surgical intensive care. Arch Surg. 2002;137(12):1353-1359; discussion 1359.

27. Gaynes R, Edwards JR; National Nosocomial Infections Surveillance System. Overview of nosocomial infections caused by gram-negative bacilli. Clin Infect Dis. 2005;41(6):848-854.

28. Donlan RM, Costerton JW. Biofilms: survival mechanisms of clinically relevant microorganisms. Clin Microbiol Rev. 2002;15(2):167-193.

29. Costerton JW, Stewart PS, Greenberg EP. Bacterial biofilms: a common cause of persistent infections. Science. 1999;284(5418):1318-1322.

30. Asati A, Santra S, Kaittanis C, Nath S, Perez JM. Oxidase-like activity of polymer-coated cerium oxide nanoparticles. Angew Chem Int Ed Engl. 2009;48(13):2308-2312.

31. Asati A, Santra S, Kaittanis C, Perez JM. Surface-charge-dependent cell localization and cytotoxicity of cerium oxide nanoparticles. ACS Nano. 2010;4(9):5321-5331.

32. Kawakubo M, Ito Y, Okimura $Y$, et al. Natural antibiotic function of a human gastric mucin against Helicobacter pylori infection. Science. Aug 13 2004;305(5686):1003-1006.
International Journal of Nanomedicine

\section{Publish your work in this journal}

The International Journal of Nanomedicine is an international, peerreviewed journal focusing on the application of nanotechnology in diagnostics, therapeutics, and drug delivery systems throughout the biomedical field. This journal is indexed on PubMed Central, MedLine, CAS, SciSearch ${ }^{\circledR}$, Current Contents ${ }^{\circledR} /$ Clinical Medicine,

\section{Dovepress}

Journal Citation Reports/Science Edition, EMBase, Scopus and the Elsevier Bibliographic databases. The manuscript management system is completely online and includes a very quick and fair peer-review system, which is all easy to use. Visit http://www.dovepress.com/ testimonials.php to read real quotes from published authors. 